\title{
ESTUDO DO USO DE CASCA DE COCO COMO BIOADSORVENTE PARA A REMOÇÃO DE ÓLEOS E GRAXAS DE EFLUENTES
}

\author{
A. S. ALMAGRO ${ }^{1 *}$, A P. MENEGUELO ${ }^{1}$, A. N. F. MENDES ${ }^{2}$ S. M. S. ROCHA ${ }^{3}$ \\ ${ }^{1}$ Universidade Federal do Espírito Santo, Departamento de Engenharias e Tecnologia \\ ${ }^{2}$ Universidade Federal do Espírito Santo, Departamento de Ciências Naturais \\ ${ }^{3}$ Universidade Federal do Espírito Santo, Departamento de Educação e Ciências Humanas \\ *e-mail: albertoalmagro@hotmail.com, sandra.m.rocha@ufes.br
}

\begin{abstract}
RESUMO
O aumento do rigor legislativo quanto às leis ambientais tem aumentado com o passar dos anos, incentivando linhas de pesquisa na área de tratamento e reutilização de águas residuárias. Em se tratando de efluentes oleosos, percebe-se uma dificuldade de tratamento utilizando os métodos convencionais, que apresentam baixa eficácia para a separação água/óleo. Assim, a operação de adsorção é uma alternativa para o tratamento desses efluentes. Entre os produtos que podem ser utilizados como adsorventes, o carvão ativado é o mais comercializado para esse fim. Porém, apesar da alta eficiência, seu uso em escala industrial é inviável devido ao seu alto custo. Dessa forma, busca-se viabilizar o emprego da adsorção no tratamento de efluentes oleosos, propondo adsorventes alternativos, com menores valores de mercado e eficiência satisfatória. $\mathrm{Na}$ realização do presente trabalho, propõe-se a utilização de fibras de coco verde como material adsorvente, já que essa biomassa é bastante abundante no norte do Espírito Santo. Com isso, também se diminui a quantidade de biomassa a ser descartada de forma errônea pelo setor agroindustrial. Para se determinar o poder adsortivo das fibras de coco, foram realizados testes em batelada avaliando a influência de variáveis como $\mathrm{pH}$, tempo de residência, concentração de adsorvente, temperatura do efluente e granulometria do adsorvente na operação de adsorção. As fibras mostraram resultados bastante satisfatórios, já que em todos os ensaios houve redução significativa da quantidade de óleos e graxas no efluente tratado.
\end{abstract}

\section{INTRODUÇÃO}

A natureza, e consequentemente a vida humana, tem sido cada vez mais prejudicada pela poluição das atividades industriais. É denominada poluição toda adição de substâncias ou formas de energia que alteram as características do corpo d'água (TUCCI, 1998).

Os efluentes industriais são, em sua maioria, descartados diretamente nos mananciais, afetando diversos corpos d'água (RAYMUNDO; RIBEIRO, 2008).
Dessa forma, os descartes líquidos das atividades industriais devem passar por tratamentos antes de serem despejados na natureza. Os efluentes oleosos são um dos principais poluentes do meio aquático. Ao serem lançados no ambiente aquático, formam um filme insolúvel na superfície da água, dificultando a aeração e iluminação adequada, prejudicando a fauna e flora local (MIOTTO, 2013).

O óleo emulsificado na água também gera graves consequências para os microrganismos responsáveis pela 
biodegradação, oferecendo perigo à saúde humana (ZHOU et al., 2008).

Para o tratamento de efluentes oleosos, a adsorção pode ser utilizada. Ela consiste em uma operação em que moléculas da fase fluida aderem a superfície sólida. Essa interação está relacionada ao desequilíbrio das forças superficiais do adsorvente, que formam um campo de força ao redor da estrutura da mesma, atraindo as moléculas de adsorbato (SCHWANKE, 2003). A operação de adsorção pode ser influenciada pela temperatura de operação, $\mathrm{pH}$ do meio, tempo de operação, concentração de adsorvente e granulometria do mesmo.

Neste contexto este trabalho tem como objetivo principal determinar a condição ótima das variáveis operacionais para a adsorção da fração de óleos e graxas do efluente oleoso em biodasorvente produzido de fibra de casca de coco verde, de forma a viabilizar o emprego de adsorção em escala industrial. Visto que a proposta de emprego de biomassa como alternativa ao carvão ativado como material adsorvente torna o procedimento mais viável economicamente, além de oferecer uma utilização nobre aos rejeitos agroindustriais.

\section{METODOLOGIA}

Para a realização do presente trabalho, coletou-se o efluente em um posto de combustíveis da região norte do Espírito Santo, este efluente é oriundo da caixa de separação óleo/água, em que todo o efluente contaminado com óleo no posto de gasolina é direcionado para esta caixa. Antes da realização dos ensaios de fato, sedimentou-se a fração sólida (areias e pedregulhos) contida no efluente bruto com o auxílio de cones Imhoff. A fração de óleos livres foi separada com o auxílio de funis de separação do tipo pêra.

As fibras de coco utilizadas como material bioadsorvente foram doadas por uma empresa de beneficiamento de água de coco da região norte do Estado do Espírito Santo. Elas passaram por um processo de lavagem, secagem e trituração com o auxílio de um moinho de jarros. Após a moagem, elas foram separadas em diferentes granulometrias com o auxílio de peneiras com mesh Tyler entre $10 \mathrm{e}$ 28 , ou seja, aberturas entre 1,7 e $0,6 \mathrm{~mm}$.

Os testes preliminares foram realizados em batelada, a agitação foi promovida por meio de agitadores magnéticos, em erlenmeyers de $250 \mathrm{~mL}$ e em triplicata. Foram adicionados $100 \mathrm{~mL}$ de efluente e as demais condições variaram de acordo com os objetivos de cada teste. A partir dos resultados de cada teste, fixava-se a condição que apresentasse maior eficiência para os testes subsequentes. Tal metodologia é análoga à utilizada por Macêdo (2013).

\subsection{Teste de $\mathbf{p H}$}

O teste preliminar para a determinação do $\mathrm{pH}$ ótimo para adsorção de óleos por fibras de coco, foi realizado mantendo o tempo de residência de 2 horas, concentração de adsorvente de 0,2 g/100 mL de efluente, temperatura ambiente (aproximadamente $25^{\circ} \mathrm{C}$ ) e granulometria de mesmo tamanho em todos os corpos de prova. Os $\mathrm{pHs}$ investigados variaram de 2 a 12, com passo de 2.

\subsection{Teste de Tempo de Detenção Hidráulica (TDH)}

De forma a se determinar o melhor tempo de detenção hidráulica (TDH) do efluente oleoso com o adsorvente, foram realizados testes preliminares. Nestes testes o valor do $\mathrm{pH}$ foi fixado em 2 , visto que este foi determinado como o melhor $\mathrm{pH}$ para a adsorção do óleo nas fibras de coco, as demais condições foram fixadas como na seção 2.1. Os tempos de residência testados foram de $10 \mathrm{~min}, 20 \mathrm{~min}, 1 \mathrm{~h}, 2 \mathrm{~h}, 3 \mathrm{~h}$ e $4 \mathrm{~h}$. 


\subsection{Teste de Concentração de Adsorvente}

De forma a se determinar a concentração de adsorvente que apresentaria a melhor remoção de teor de óleos e graxas, foram realizados testes preliminares para as concentrações $0,1 \mathrm{~g}, 0,2 \mathrm{~g}, 1,0 \mathrm{~g}, 2,0 \mathrm{~g}, 3,0 \mathrm{~g}$ e 4,0 $\mathrm{g}$ de fibras de coco para cada $100 \mathrm{~mL}$ de efluente. Os ensaios ocorreram sob $\mathrm{pH}=2,0 \mathrm{e}$ TDH de $1 \mathrm{~h}$, as demais condições foram fixadas de acordo com a seção 2.1.

\subsection{Teste de Temperatura}

Foram realizados testes preliminares para determinar a melhor temperatura de operação do sistema. Para tal fixou-se os valores de $\mathrm{pH}=2,0, \mathrm{TDH}$ de $1 \mathrm{~h}$ e concentração de $0,2 \mathrm{~g}$ de fibras por $100 \mathrm{~mL}$ de efluente. As temperaturas investigadas foram as de $25^{\circ} \mathrm{C}$ (ambiente), $40^{\circ} \mathrm{C}, 50^{\circ} \mathrm{C}, 60^{\circ} \mathrm{C}$ e $70^{\circ} \mathrm{C}$.

\subsection{Teste de Granulometria}

Neste teste, avaliou-se a influência do tamanho das partículas de fibra de coco. Foram investigadas as faixas granulométricas das fibras retidas entre as peneiras de mesh $10,14,20,24,28$ e fundo. Novamente, fixaram-se as condições ótimas determinadas anteriormente.

\subsection{Teste de Pré-Tratamento Químico}

Este teste ocorreu sob as condições determinadas nos testes preliminares descritos anteriormente. As fibras de coco passaram por dois pré-tratamentos químicos distintos: ácido ou básico. Foram mantidas em contato com soluções de $\mathrm{HCl}$ ou $\mathrm{NaOH}$ (ambos na concentração de $0,05 \mathrm{~mol} / \mathrm{L})$ por 48 h. Após serem lavadas até $\mathrm{pH}$ neutro e secas novamente, realizou-se $o$ teste para determinação se algum pré-tratamento potencializa a adsorção de óleos por parte das fibras de coco.

\subsection{Determinação do Teor de Óleos e Graxas (TOG)}

Os Teores de Óleos e Graxas (TOG) do efluente bruto e tratado após cada teste foram determinados pelo método gravimétrico adaptado do Standard Methods (APHA, 2012).

O método gravimétrico consiste na extração da fase orgânica da fase aquosa utilizando hexano como solvente. Para isso, retirou-se uma alíquota de $25 \mathrm{~mL}$ de cada amostra de efluente e realizou-se a extração com três doses de $10 \mathrm{~mL}$ do solvente. Considerando que todo o óleo presente no efluente estava contido na fase orgânica, separou-se a mesma para um béquer previamente limpo, seco e tarado. Evaporouse, portanto, todo o hexano com o auxílio de uma estufa a $100^{\circ} \mathrm{C}$, até que restasse somente o óleo contido na alíquota original. A diferença de massa do béquer novamente pesado com a tara anterior foi considerada como a massa de óleo contida na amostra de $25 \mathrm{~mL}$.

O TOG, portanto, foi determinado em $\mathrm{mg} / \mathrm{L}$ a partir da Equação 1.

$$
T O G=\frac{(M F-M I) * 1000}{V}
$$

Em que MF é a massa final do béquer, MI é a massa inicial do béquer e $\mathrm{V}$ é o volume em litros da alíquota testada $(0,025$ L).

O percentual de remoção de TOG foi estimado de acordo com a Equação 2.

$$
\% T O G=\frac{T O G_{t=0}-T O G_{t=x}}{T O G_{t=0}} \cdot 100
$$

Em que: TOG $_{\mathrm{t}=0}$ é o Teor de Óleos e Graxas do efluente virgem $(710 \mathrm{mg} / \mathrm{L})$ e $\mathrm{TOG}_{\mathrm{t}=\mathrm{x}}$ é o TOG realizado após a adsorção.

As condições que apresentaram maiores \% TOG foram consideradas ótimas e fixadas nos experimentos subsequentes. 


\section{RESULTADOS E DISCUSSÃO}

\subsection{Teste de $\mathbf{p H}$}

A Figura 1 representa os dados obtidos através do teste de influência de $\mathrm{pH}$ na adsorção de efluente oleoso utilizando fibras de coco.

Figura 1 - Influência do pH na adsorção.

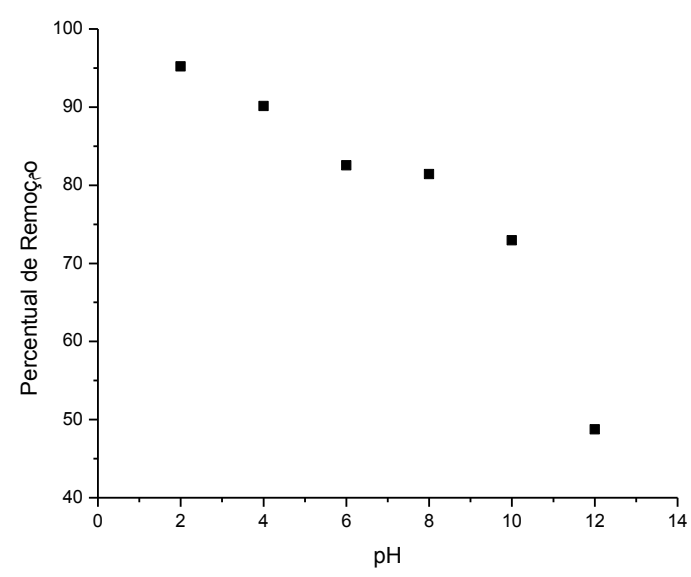

A análise da Figura 1 nos permite verificar que houve uma maior redução de óleo emulsificado nas amostras com $\mathrm{pH}=2$. Isso provavelmente ocorre devido à carga elétrica componente dos sítios ativos nas fibras de coco. Além disso, de acordo com Monteiro (2006), o pH mais baixo facilita a quebra de emulsão oleosa. Essa combinação de fatores sugere que quanto menor o $\mathrm{pH}$ do meio, mais forte é a ligação do óleo no adsorvente.

\subsection{Teste de Tempo}

A Tabela 2 representa os dados obtidos através do teste de influência de tempo na adsorção de efluente oleoso utilizando fibras de coco.
Tabela 2 - Resultados obtidos através do teste de influência do tempo.

\begin{tabular}{ccc}
\hline $\begin{array}{c}\text { Tempo de ensaio } \\
\text { (min) }\end{array}$ & $\begin{array}{c}\text { TOG } \\
\text { (mg/L) }\end{array}$ & \% TOG \\
\hline 10 & $142 \pm 42$ & 80,00 \\
20 & $178 \pm 8$ & 74,93 \\
60 & $30 \pm 14$ & 95,77 \\
120 & $164 \pm 17$ & 76,90 \\
240 & $158 \pm 31$ & 77,75 \\
\hline
\end{tabular}

Nota-se que não há tendência linear quanto à influência no tempo de exposição das amostras na adsorção. A análise dos dados permite concluir que o tempo de 60 min se apresentou como melhor condição. Além disso, a Tabela 2 mostra que a porcentagem de remoção de óleo se mantinha entre 70 e 80, atinge um pico no tempo de 60 min e retorna à porcentagem de remoção semelhante ao anterior. Isso pode indicar que $\mathrm{o}$ adsorvente atinge um estado de saturação e posteriormente alcança o estágio de dessorção, ou seja, o óleo passa a retornar para o efluente. Analisando com mais esmero os resultados, pode-se deduzir que este processo de saturação e dessorção ocorre continuamente, pois o ponto de máxima adsorção ocorre em um momento intermediário no intervalo estudado.

\subsection{Teste de Concentração de Adsorvente}

A Tabela 3 representa os dados obtidos através do teste de influência da concentração de adsorvente na adsorção de efluente oleoso utilizando fibras de coco. 
Tabela 3 - Resultados obtidos através do teste de influência da concentração de adsorvente.

\begin{tabular}{ccc}
\hline $\begin{array}{c}\text { Concentração de } \\
\text { Adsorvente } \\
\text { (g/100mL de } \\
\text { efluente) }\end{array}$ & $\begin{array}{c}\text { TOG } \\
\text { (mg/L) }\end{array}$ & \% TOG \\
\hline 0,1 & $174 \pm 31$ & 75,49 \\
0,2 & $134 \pm 20$ & 81,12 \\
1,0 & $160 \pm 28$ & 77,46 \\
2,0 & $262 \pm 37$ & 63,10 \\
3,0 & $182 \pm 14$ & 74,37 \\
5,0 & $180 \pm 28$ & 74,65 \\
\hline
\end{tabular}

A análise dos dados sugere que a concentração de adsorvente não é uma variável da operação de adsorção de efluentes oleosos utilizando fibras de coco. Apesar disso, a concentração de $0,2 \mathrm{~g}$ de adsorvente/100 mL de solução apresentou ligeira superioridade de eficiência em relação às demais.

\subsection{Teste de Temperatura}

A Figura 4 representa os dados obtidos através do teste de influência da temperatura na adsorção de efluente oleoso utilizando fibras de coco.

Figura 4 - Influência da temperatura na adsorção.

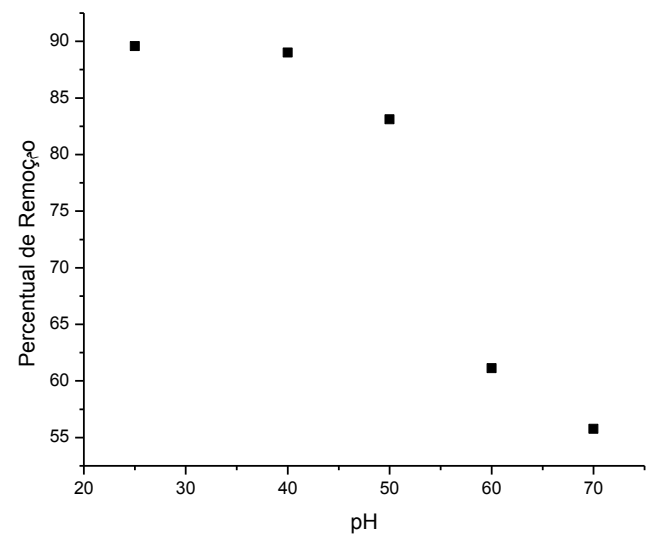

A análise dos dados sugere que o aumento da temperatura dificulta a adsorção. Isso se deve ao provável caráter exotérmico da interação entre adsorvente e adsorvato. Além disso, nota-se que as amostras nas temperaturas ambiente (considerando $25^{\circ} \mathrm{C}$ ) e de $4^{\circ} \mathrm{C}$ apresentam percentagem de remoção semelhantes. Considerando a necessidade de processos industriais com maiores eficiências energéticas, adotou-se a temperatura ambiente como a temperatura ótima para realização dos testes seguintes.

\subsection{Teste de Granulometria}

A Tabela 5 representa os dados obtidos através do teste de influência da granulometria na adsorção de efluente oleoso utilizando fibras de coco.

Tabela 5 - Resultados obtidos através do teste de influência da granulometria.

\begin{tabular}{ccc}
\hline Mesh Tyler & TOG $(\mathbf{m g} / \mathbf{L})$ & \% TOG \\
\hline+10 & $350 \pm 8$ & 50,70 \\
$-10+14$ & $124 \pm 23$ & 82,53 \\
$-14+20$ & $304 \pm 6$ & 57,18 \\
$-20+24$ & $256 \pm 28$ & 63,94 \\
$-24+28$ & $58 \pm 3$ & 91,83 \\
Fundo & $94 \pm 31$ & 86,76 \\
\hline
\end{tabular}

A análise dos dados sugere que não há tendência na influência na granulometria na adsorção. Porém, ao se descartar os dados obtidos para o intervalo mesh-Tyler $(-10+14)$ - adotando uma possível falha de execução do experimento -, nota-se que os resultados apontam para uma eficiência maior quanto menor é a partícula. Isso era esperado, visto que quanto menor a partícula adsorvente, maior é a área de contato com o efluente. Uma maior área de contato provê uma maior quantidade de sítios ativos expostos, potencializando a adsorção. 


\subsection{Teste de Pré-Tratamento Químico}

A Figura 6 representa os dados obtidos através do teste de influência do prétratamento na adsorção de efluente oleoso utilizando fibras de coco.

Figura 6 - Influência do tipo de pré-tratamento na adsorção.

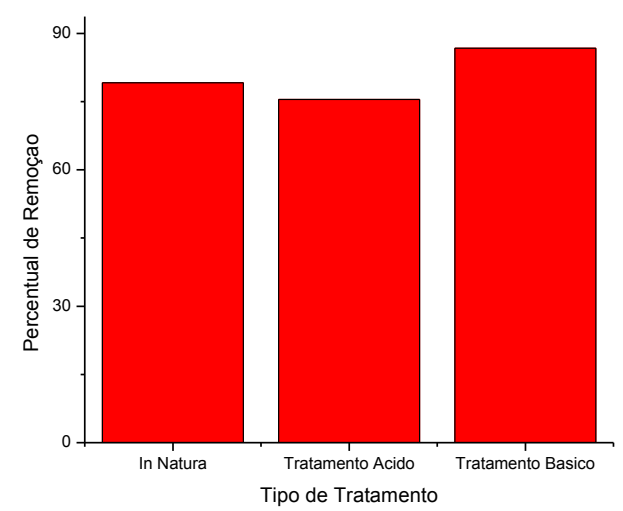

Ao se analisar os resultados obtidos, observa-se que o tratamento básico ofereceu os melhores resultados.

De acordo com Albinante et al. (2013), isso ocorre devido à formação de rugosidades na superfície da fibra, melhorando a aderência mecânica e aumentando a superfície de contato. Essas rugosidades se devem à solubilização da hemicelulose em meio álcali e ao processo de hidrólise da celulose, que ocorre sob essas condições.

\section{CONCLUSÃO}

A análise dos resultados obtidos permite concluir que as fibras de coco possuem alta capacidade de adsorção. Isso se percebe devido ao fato de ter havido redução de TOG em todos os ensaios. O efluente oleoso pode, portanto, ser tratado utilizando esses rejeitos da indústria agrícola, solucionando dois problemas de descarte para o meio ambiente.
A metodologia empregada, de ensaios em batelada, se mostrou satisfatória, por sua simplicidade e facilidade de execução e reprodução. Isso motiva a continuação dessa linha de pesquisa, buscando outros materiais bioadsorventes.

\section{NOMENCLATURA}

\%TOG - Porcentagem de remoção de óleos de graxas;

MF - Massa final do béquer [g];

MI - Massa inicial do béquer [g];

pH - Potencial hidrogeniônico;

TOG - Teor de Óleos e Graxas;

TOG $_{t=0}$ - Teor de Óleos e Graxas do efluente virgem [ppm];

TOG $_{t=x}$ - Teor de Óleos e Graxas em um tempo x qualquer;

V - Volume da alíquota [L];

\section{REFERÊNCIAS}

ALBINANTE, S. R.; PACHECO, E. B. A. V.; VISCONTE, L. L. Y. Revisão dos Tratamentos Químicos da Fibra Natural para Mistura com Poliolefinas. Química Nova, v. 36, n. 1, p. 114-122, 2013.

APHA, A. W. Standart Methrods for examination of Water and wastewater. American Public Health Association. Washington: 2012. p. 1360.

MACÊDO, J. A. B. D. Métodos Laboratoriais de Análises Físico-Químicas e Microbiológicas. $4^{\mathrm{a}}$ Ed. Editora: CRQ-MG, 2013.

MIOTTO, N. Hidrotalcita Hidrofóbica e Magnética Aplicada no Tratamento de Efluentes Oleosos. Dissertação submetida ao Programa de Pós-Graduação em Engenharia Química da Universidade Federal de Santa Catarina. Florianópolis. 2013. 
MONTEIRO, M. I. Tratamento de Efluentes Oleosos Provenientes da Indústria Metal-Mecânica e Seu Reúso. Tese Apresentada à Escola de Engenharia de Lorena da Universidade de São Paulo. Lorena/SP: 2006.

RAYMUNDO, A. S.; RIBEIRO, A. V. F. N. Estudo da Casca/Palha de Café como Adsorvente Natural para Remoção de Corante Têxtil. III Jornada de Iniciação Científica do Cefetes e I Jornada de Iniciação em Desenvolvimento Tenológico e Inovação. Vitória: 2008. p. 20-21.

SCHWANKE, R. O. Determinação da difusividade de hidrocarbonetos aromáticos em zeólitas $Y$ por métodos cromatográficos. Dissertação de Mestrado em Engenharia Química - Programa de PósGraduação em Engenharia Química - PPGEQ. Universidade Federal de Santa Catarina. UFSC: 2003. p. 115.

TUCCI, C. E. M. Modelos Hidrológicos. Porto Alegre: Ed. da Universidade/UFRGS/ABRH. 1998. 669 p.

ZHOU, Y, B; TANG X,Y; HU, X, M; FRITSCHI, S; LU, J. Emulsified oily wastewater treatment using an hybridmodified resin and activated carbon system. Separation and Purification Technology, v. 63, p. 400-406, 2008. 